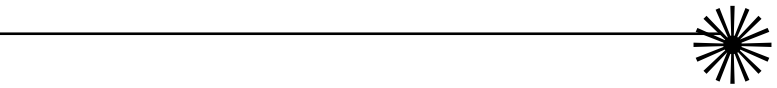

\title{
REDES MUSICAIS E (RE)COMPOSIÇÕES TERRITORIAIS NO PRATA: POR UMA
}

\author{
GEOGRAFIA DA MÚSICA
}

- LUCAS MANASSI PANITZ*

Resumo: Este artigo trata das relaçães entre as redes musicais no espaço platino e suas repercussões territoriais. A partir de um desenho de pesquisa multilacalizada, buscau-se entender coma se deu a pracessa de farmaçãa de algumas das atuais redes musicais transfronteiriças entre Argentina, Brasil e Uruguai. Para issa, articulamos quatro eixas. ( primeira expõe um breve histórica da Geggrafia da Música. ( s segunda trata da presente construção teórica e metadalógica da pesquisa. 7 terceiro eixo atenta para as represent[ações] gengrafizantes e territorializantes, valorizanda tanto as representaçães do espaço quanto as práticas espaciais. [ quarto eixo defende que as redes musicais em questão promavem uma [re]compasiçãa territarial da cultura no Prata, transculturanda referenciais brasileiros e rioplatenses, tradicionais e contemparâneos, e idiomas e gêneros musicais. Nessa [re]composiçãa, cidades camo Porto Alegre, Pelotas, Buenos Aires e Montevidéu, apontam para uma rede de produçãa cultural colada a um imaginário gegrráfica transfranteiriça. Por fim, o autor chama a atençãa para a compreensão das redes musicais como forma de desvelar outras integrações culturais, políticas e econômicas na América do Sul.

Palavras-Chave: Geggrafia da Música; espaço platina; estética do frio; redes musicais.

\section{Introdução}

O presente trabalho conclui um conjunto de textos que buscou desenvolver elementos teóricos e metodológicos de uma Geografia da Música partindo da experiência de nossa pesquisa no contexto platino (PANITZ, 2017) ${ }^{1}$. Inicialmente trouxemos elementos históricos da constituição deste campo de estudo no Brasil e no mundo (PANITZ, 2012a, 2012b); posteriormente desenvolvemos um 
quadro metodológico para uma pesquisa multilocalizada, em diálogo com a antropologia (PANITZ e MURILLO, 2016); por fim apresentamos os resultados parciais da pesquisa que apontavam para a formação de uma rede musical transfronteiriça no espaço platino (PANITZ, 2016). A pesquisa foi desenvolvida entre 2009 e 2016, acompanhando músicos independentes da Argentina, Brasil e Uruguai, bem como mapeando eventos e iniciativas culturais que colocavam a música como elemento privilegiado para a discussão sobre a cultura platina. Neste texto apresentamos três eixos. No primeiro, expomos as opções teóricas e a proposta de um desenho de pesquisa multilocalizado. No segundo eixo, mostramos os resultados da pesquisa. Em um primeiro momento construímos a noção de espaço platino a partir uma miríade de realidades geográficas sobrepostas (Bacia do Rio de Prata, Pampa, Cone Sul, Mercosul). Em seguida, mostramos como as representações geografizantes dos artistas em questão produzem representações do espaço platino. Por fim, as represent(ações) territorializantes têm como foco a formação das redes, das práticas musicais e iniciativas culturais, desvendando, assim, o território. No terceiro eixo, defendemos que as redes musicais em questão promovem uma [re $]$ composição territorial da cultura no Prata, transculturando referenciais brasileiros e rioplatenses, tradicionais e contemporâneos, misturando idiomas e gêneros musicais. Nessa [re]composição territorial, cidades como Porto Alegre, Pelotas, Buenos Aires e Montevidéu apontam para uma rede de produção cultural densa, colada a um imaginário geográfico transfronteiriço. Por fim, os autores chamam a atenção para a compreensão das redes musicais como forma de desvelar outras integrações culturais, políticas e econômicas na América do Sul.

\section{A Geografia da Música: uma brevíssima arqueologia do campo}

Ao contrário do que se possa imaginar, o interesse da Geografia pela música não aparece no giro cultural dos anos 1980, quando decorridas as reorientações teóricas nas ciências sociais de base anglófona. Como observa Reynoso (2006), as primeiras considerações que ligam a Geografia moderna à expressão musical podem ser atribuídas ao etnólogo e arqueólogo africanista Leo Frobenius, discípulo de Friedrich Ratzel. Atento aos indícios da cultura material, Frobenius realizou estudo da difusão e morfologia dos tambores, que o levou a desenvolver a 
noção de Círculos Culturais (Kulturkreis) junto aos etnólogos austríacos Fritz Graebner e Wilhelm Schimidt. Partindo dessa noção, a partir do estudo da distribuição espacial de instrumentos musicais, entre outros procedimentos, Frobenius estabeleceu regionalizações na África que remetem aos ciclos de difusão de etnias.

Já no início do século XX, o geógrafo francês Gironcourt (1927) propõe nominalmente uma 'Geografia musical' como novo campo de estudos, nos Annales de Géographie da Associação Francesa de Geografia, tendo realizado diversos estudos na Tunísia, Java e Camboja. Com a intenção de estabelecer um novo campo de estudo na Geografia, o autor afirma que "pode-se admitir que o repertório de sons eles mesmos e de suas associações em combinações musicais foram até agora negligenciados pelos geógrafos" (idem, p. 292). Segundo o autor, a Geografia musical deveria se debruçar sobre as formas musicais através do espaço e do tempo, permitindo analisar a fixação e a mobilidade de sociedades e civilizações. A simples introdução, por exemplo, de certo tipo de chocalho em uma banda de jazz norte-americana poderia - segundo o autor - dar informações importantes sobre a origem étnica e geográfica de determinados grupos, mas também de instrumentos e formas musicais que vão se transformando e se adaptando a cada sociedade em que são inseridos. É assim que, em trabalho posterior, Gironcourt (1939) expõe alguns dos resultados pessoais coletados ao longo de doze anos dedicados ao tema, desde seu artigo seminal advogando pela nova disciplina geográfica. No referido texto, o autor afirma, por meio de diversos estudos realizados por ele, que é possível recompor a mobilidade de populações e suas origens através das formas musicais, pois essas formas permanecem no tempo e no espaço ao longo da história humana ou se modificam levando algumas características pretéritas para outros lugares: ou seja, há um caráter de fixidade e um caráter de mobilidade dos grupos humanos que podem ser estudados por intermédio da música.

Nas últimas três décadas, vemos importantes obras organizadas por geógrafas/os como Kong (1995, 1997), Leyshon et al (1998), Lévy (1999), Raibaud (2006, 2011), Guiu (2006) Canova \& Augustín (2014), entre outros. Nestes/as autores/as é claro o entendimento da música ela mesma como uma espacialidade, engendrada por outras espacialidades e territorialidades. Isso porque a música é produzida e difundida pelo espaço, se conecta aos objetos geográficos (como 
estúdios, gravadoras, lojas, redes de distribuição e difusão etc), se alimenta das tradições musicais territorializadas e produz imaginários geográficos através das letras das canções, dos arranjos e texturas musicais.

No Brasil, após o trabalho pioneiro de Baptista (1991) lançando um olhar da Geografia humanista sobre a canção no Rio de Janeiro, percebe-se a emergência de um fecundo campo de estudos para o país bem como para a América Latina. Panitz (2012a, 2012b), destaca a profusão de trabalhos em âmbito brasileiro nas últimas duas décadas. Uma parte significativa destas pesquisas estão publicadas em obras organizadas por Dorfman, Heidrich e Panitz (2012) e Dozena (2016, 2018), percorrendo inúmeras manifestações da música em diversas regiões do Brasil. Com mais de quarenta trabalhos publicados entre teses e dissertações, além de dezenas de artigos sobre a temática, é possível afirmar que a música constitui hoje um campo de interesse em pleno desenvolvimento. Os tratamentos teóricos e metodológicos são diversos como é diversa a própria Geografia brasileira. No que concerne ao presente artigo, será mostrada na próxima seção uma opção teórica que considera as representações do espaço como representações sociais, e a escolha de um trabalho de campo multilocalizado para dar conta dos fluxos culturais transfronteiriços.

\section{Notas sobre uma pesquisa geográfica} sobre música

A música em geral, mas sobretudo a canção - enquanto um híbrido entre a forma literária e musical - possui a capacidade de representar o mundo, criar discursos e lançar interpretações sobre este mundo. Mas quem o faz é um ser social, e sua expressão não está somente confinada ao contexto artístico a que participa. A música fala da sociedade, da cultura, da política, e é incorporada nos discursos cotidianos. Daí a importância de pensar em termos de representação social, ou seja, de uma forma de conhecimento da realidade que é criada por um indivíduo ou grupo, para ser partilhada entre grupo ou grupos de indivíduos, tal como afirma Jodelet (2001). Sendo assim, toda a representação é social, pois serve para dar sentido e orientação às ações humanas. As representações sociais, enquanto "sistemas de interpretação que regem nossa relação com o mundo e com os outros - orientam e organizam as condutas e as comunicações sociais" intervêm, portanto, "em processos variados, tais como a difusão e a assimilação dos conhecimentos, o desenvolvimento individual e coletivo, a 
definição das identidades pessoais e sociais, a expressão dos grupos e as transformações sociais" (idem, p.22). As representações sociais são, portanto, mais um processo em construção que algo estanque; seu estudo se interessa mais na inovação que na tradição, mais na vida social em via de se fazer do que uma vida social já feita, tal como afirma Moscovici (2001). Não discordamos de que o ato de representar algo, como afirma Marin (apud LUSSAULT, 2007, p.72) é “a anunciação poderosa de uma absência”, mas completamos que o ato de tornar presente algo que não está lá possui intencionalidades intrínsecas ao ator, seja individual ou coletivo, e sua enunciação cumpre uma função dentro de uma realidade social e geográfica. As representações do espaço, tal como a entendemos aqui, se incluem nessa abordagem, pois representar o espaço é um ato social que visa criar uma ideia de espaço. Essa ideia comunica valores, percepções, significados, que estão sempre situados histórica e geograficamente. Nesta perspectiva, nos distanciamos aqui de uma visão que evoca a representação do espaço somente como uma imagem da materialidade geográfica, externa ao humano, mas como um ato de representar a própria existência humana, que é inexoravelmente espacial (LUSSAUT,
2007). Este ato de representar o espaço é feito via linguagem - que como entende Hall (1997) não se limita à escrita, mas à fala, aos gestos, às formas visuais, musicais, etc. Ou seja, a linguagem é performativa. Todo ato linguístico, nos lembra Lussault (idem), é sempre um ato social, dotado de uma performance e investido de uma espacialidade. Representar o espaço, portanto, é uma prática espacial - por isso a chamamos aqui de represent[ação], entendida como discurso e prática.

A música está presente em todas as sociedades, de forma que podemos considerá-la como uma característica inerente à espécie humana. Como afirma Aubert (1991, p.11) " [ tal como a linguagem articulada], ela [a música] é produto de uma experiência coletiva respondendo a um conjunto de necessidades culturais determinantes". Sendo na contemporaneidade o produto artístico mais presente no cotidiano humano, tem a capacidade de colocar em trânsito uma grande quantidade de representações sociais e do espaço. Em termos de análise geográfica, é necessário estar atento ao conteúdo das representações do espaço e das práticas no espaço, e de que forma elas se combinam na produção - no presente caso - de territórios, sempre entendidos em sua natureza múltipla (HAESBAERT, 2007). 
E porque o fenômeno musical geografiza e territorializa, ele move-se. Faz-se necessário, então, um método para o trabalho de campo que dê conta deste movimento.

Visualizamos um potencial de estudo na proposta da multisited etnography de Marcus (1995). Esse autor advoga pela necessidade de um trabalho etnográfico que participe do fluxo, seguindo pessoas, objetos e ideias, registrando os contextos de circulação e suas transformações no tempo e no espaço. Em uma releitura dessa proposta, Panitz e Murilo (2016) atentam para a importância de seguir também a própria espacialidade das redes e fluxos. Sendo assim, partimos de uma concepção de um campo geográfico multilocalizado, acompanhando a rede de músicos em questão, registrando as represent(ações) com vistas a compreender como e através de quais contextos uma territorialidade musical é produzida. Nessa proposta, realizamos trabalhos de campo em cidades da Argentina, Brasil e Uruguai, situandose onde os artistas se encontravam, e acompanhando-os em apresentações, ensaios, turnês e gravações.

\section{As represent[ações] da música} popular no Prata

A denominação 'espaço platino’ pode, de início, suscitar dúvidas, haja vista seu uso corrente ser feito sem uma conceituação mais clara. Enquanto quadro natural, o espaço platino é representado pelo Pampa, os campos sul-americanos onde predominam relevos de planície e vegetações gramíneas e arbustivas (BENCKE et al, 2016), paisagem também fruto da ocupação histórica da pecuária e que se tornou emblemática na cultura gaucha/gaúcha. Também visualizamos a Região Platina Colonial, que conforme Gutfreind e Reichel (1996) se apresenta como formação socioespacial baseada na atividade pastoril e na ocupação do pampa, na qual o caráter móvel da fronteira e, mais adiante, a própria cultura fronteiriça, se fizeram características bem marcantes. A Bacia do Prata, por sua vez, contribui para a compreensão dos deslocamentos internos, de ordem fluvial, determinantes para a própria ocupação colonial e para as disputas territoriais entre os séculos XVI e XIX. Numa abordagem histórica e geopolítica, Rapoport e Cervo (2002) defendem o Cone Sul como um subsistema na América Latina, no qual os países compartilham problemas de ordem social e econômica e guardam aspectos identitários 
semelhantes. Do ponto de vista geopolítico e econômico mais atual, Ruckert e Dietz (2013) destacam o Núcleo Geoeconômico do Mercosul como um recorte para entender os processos contemporâneos de integração no Mercosul - este, fruto da dinâmica de integração regional via bloco econômico a partir da década de 1990. Mas nenhuma dessas denominações satisfaz individualmente as indagações deste trabalho. O reconhecimento do conjunto destas dimensões nos ajudará na construção da noção de espaço platino (Figura 1). Nomeá-lo assim aponta para a compreensão do espaço geográfico como conceito chave que permite desvelar as múltiplas dimensões da realidade espacial tomando-as como categorias (SANTOS, 2009; SUERTEGARAY, 2001) ou feiçõesespaço (HEIDRICH, 2013), que permitem apreender o empírico e realimentar o teórico. Ao considerarmos a paisagem como realidade morfológica e cultural, a herança das raízes coloniais já retrabalhadas, o processo de formação das fronteiras nacionais e os processos atuais de integração, defende-se a existência de um espaço geográfico complexo, que contêm distintas realidades materiais que enredadas pelas representações e ações humanas corroboram para a ideia de um espaço platino.

\subsection{As representações geografizantes}

Vitor Ramil, compositor e escritor brasileiro, publicou um ensaio denominado A estética do frio (RAMIL, 1993) onde realiza algumas reflexões da sua própria criação musical e uma tentativa de sistematizar essas reflexões e criar uma concepção contemporânea da música brasileira que fosse tipicamente do sul. Nos tempos em que estava radicado no Rio de Janeiro, Ramil acompanhava em junho o noticiário nacional que mostrava imagens de festas populares na Bahia em pleno clima tropical, ao lado de imagens da geada no inverno no Rio Grande do Sul, as temperaturas negativas e o cotidiano das pessoas naquele ambiente que eram mostrados num tom de anormalidade,

\begin{tabular}{|c|c|c|}
\hline \multicolumn{3}{|c|}{ Os componentes do Espaço Platino } \\
\hline Paisagem & \multicolumn{1}{|c|}{ Região } & \multicolumn{1}{c|}{ Território } \\
\hline Pampa, Bacia do Prata & $\begin{array}{l}\text { Platina Colonial (secs.XVI- } \\
\text { XIX), Conesul (sec. XX) }\end{array}$ & $\begin{array}{l}\text { Disputas Territoriais e Fronteiras } \\
\text { (secs.XV-XIX); Mercosul, } \\
\text { Mercocidades e IIRSA (secs.XX e XXI) }\end{array}$ \\
\hline
\end{tabular}

Figura 1: O espaço platino em suas distintas realidades geográficas. Elaborado por Lucas Panitz. 
como se estivessem descoladas da realidade do Brasil, ou chegassem mesmo de outro país. Ramil notou que, embora o frio estivesse presente em outros estados, havia uma representação recorrente que ligava a imagem do gaúcho ${ }^{2}$ a esse contexto climático. Da mesma forma, para além da representação, o autor nota que o frio está presente de fato no cotidiano desse lugar e que essa seria uma metáfora definidora para a criação. Passou então a buscar representações "frias", mergulhando no imaginário regional e na sua própria percepção: a figura do gaúcho, o hábito do chimarrão, o verde dos campos, sempre com poucos elementos formando a paisagem. E logo após, o compositor traçou um paralelo entre a paisagem e o ritmo da milonga, criando analogias entre ambos: “A milonga em tom menor, reflexiva, densa, profunda e melancólica. Rigorosa em sua cadência, seu ponteio, seu fraseado; sutil em seu movimento melódico sinuoso, oriental" (Ramil, 1993, p.268). A partir dessa concepção, Ramil estabelece características para sua produção: "O ritmo brasileiro, negro, dançante, tratado com certa dureza (o rigor do tango) e preciosismo planejados. O ritmo como um raciocínio minucioso. [...] O ritmo trazendo leveza. Limpeza. Uma analogia? Montanhas e morros do Rio colocados aqui e ali, criteriosamente, na vastidão lisa do pampa” (idem). Percebe-se claramente que Milonga em Sete Cidades (Ramil, 1997) é um tipo canção-manifesto das ideias que propõe.

Fiz a milonga em sete cidades / Rigor, Profundidade, Clareza / Em Concisão, Pureza, Leveza e Melancolia / Milonga é feita solta no tempo / Jamais milonga solta no espaço / Sete cidades frias são sua morada / Em Clareza / O pampa infinito e exato me fez andar / Em Rigor eu me entreguei / Aos caminhos mais sutis / Em Profundidade / A minha alma eu encontrei / E me vi em mim [...]

Para ele, a milonga enquanto ritmosíntese de sua proposta musical nunca está solta no espaço, somente no tempo, pois ela perdura através das gerações. As cidades "frias" são atributos estéticos e conceituais por onde o artista filtra sua criação musical. Mais adiante, em Indo ao Pampa (idem), o autor trata de elementos claros de geograficidade aos termos de Relph (1979) e Dardel (1952), onde o artista se encontra na paisagem ao mesmo tempo em que esta se encontra nele, e nos leva igualmente à reflexão da paisagem-marca e paisagemmatriz tal como propõe Berque (1998):

Vou num carro são / Sigo essa frente fria / Pampa a dentro e através / Desde o que é Libres sigo livre / E me espalho sob o céu / Que estende tanta luz no 
campo verde a meus pés / O que vejo lá? / Mata nativa instiga o olho que só visa me levar /Sobe fumaça branca e a pupila se abre pra avisar / Se há fumaça, há Farrapos por lá / Eu acho que é bem / Eu indo ao pampa / O pampa indo em mim (Ramil, 1997).

Do outro lado da fronteira platina, os músicos uruguaios, irmãos, Jorge e Daniel Drexler, criam o termo Templadismo - uma alusão ao Tropicalismo. De fato, no bojo dessa concepção, assim como na Estética do Frio, está uma característica que acompanha o espaço vivido no que tange o clima e suas estações bem definidas, bem como suas respectivas imagens e sensações associadas- como a melancolia, por exemplo. Para Daniel Drexler a melancolia está claramente associada ao clima e à paisagem e afirma também que " $E l$ templadismo forma una especie de corriente musical del sur latinoamericano, que se caracteriza por el no exceso, donde reinan colores, sonidos y climas calmos" (HOY, 2007). Daniel Drexler também explica que a denominação Templadismo surgiu a partir de conversas com seu irmão Jorge, sobre a Estética do frio, o tropicalismo e o Manifesto Antropófago e ocorreu-lhe teorizar em tom de brincadeira sobre um tropicalismo dos pampas: "Si tuviera que definir el templadismo en pocas palabras, te diría que es una especie de marco teórico para la creación (en mi caso de canciones) desde la cuenca del Río de la Plata" (idem). Já o compositor argentino Kevin Johansen fala em "Subtropicalismo" e também corrobora com a proposta do Templadismo e da Estética do Frio. Em entrevista concedida para esta pesquisa, o compositor afirma que reconhece uma cultura específica no âmbito platino e que

se dice que del Sur del Rio Grande do Sul, somos más tangueros, más melancolicos. [...] Tambien suelo decir que somos 'Subtropicalistas', primero por el clima, que marca a todas las culturas y segundo porque [...] nuestros padres artisticos son los Tropicalistas. [...] Eso es ser del Plata para mi.

Tanto para a uruguaia Ana Prada quanto para Kevin a cultura platina se expressa pela diversidade, pela mistura, pelo caráter histórico da miscigenação de etnias e, por conseguinte, de ritmos. Kevin afirma que "el contacto con el Atlantico, la mezcla del indio con el europeo y, aqui al sur, la resonancia del africano, que dejó su huella, su sonido". Ana Prada conta que uma característica importante da cultura do Prata se expressa pela diversidade: "En esa variedad conviven la melancolía y el ritmo, el desarraigo y el nacionalismo, la intolerancia y los intolerados, el frío y el calor, los grises y el 
colorido". Um exemplo onde se pode notar como os artistas elaboram essas ideias no plano da canção, se encontra na canção Riconcito, de Daniel Drexler. Nesta canção o artista (DREXLER, 2010) oferece elementos de geograficidade, mas também do reconhecimento da história e da diversidade cultural da região:

Rinconcito suavemente ondulado, manto verde de mi sueño, balconcito sobre el mar. I El reflejo de la luz en tu pradera, dibujando un horizonte que parece respirar. / Voy volando sobre cuchillas y lomas del Cuareim al Uruguay. / Vuelvo al río de la Plata como vuelve el agua al mar. [...] En el eco de tus cuchillas y lomas se entreveran tres idiomas, se entremezclan al hablar. / Con la misma fuerza con que te abandono siento que la gravedad me devuelve a tu regazo como vuelve el agua al mar.

Notamos, a partir destes músicos, por um lado o reconhecimento da formação histórica que dá origem à configuração étnica e cultural no espaço platino, mas também uma concepção ligada sobretudo à paisagem e ao ambiente natural, destacando o pampa e o caráter subtropical que marca esse ambiente. Longe de ser uma concepção determinista da cultura, tais assertivas levam a considerarmos o entrelaçamento entre natureza e cultura.
Como afirma Jovchelovitch (2004, p.2 1) "a representação é tanto social como está enredada na materialidade mundo”. Nesse sentido é inviável levar em conta as representações dos músicos em questão se não se levar em conta também a materialidade sobre a qual são construídas as representações. Dessa forma, se percebe uma forte dimensão geografizante nas representações dos artistas. Elas trazem elementos da materialidade do espaço geográfico para a criação estética, tornando essa materialidade viva e indispensável na própria concepção musical. Como veremos a seguir, essa dimensão dará suporte para propostas territorializantes, visando $\mathrm{O}$ campo da ação dos artistas no espaço e gerando territorialidades específicas.

\subsection{As represent[ações] territorializantes}

Vitor Ramil é apontado por muitos dos entrevistados da pesquisa como o músico que colocou em manifesto a contestação do centro (sudeste) do Brasil como único espaço de circulação cultural nacional. E ao fazê-lo, levou consigo não só brasileiros, mas argentinos e uruguaios a buscarem também um intercâmbio na região. O artista encerra desta forma o seu ensaio A Estética do frio: 
Depois da novela Pequod e de Ramilonga, realizei um disco chamado Tambong. Gravado em Buenos Aires, Argentina, este trabalho promoveu um encontro de músicos platinos e brasileiros, do Sul, Centro e Nordeste do Brasil. Sua motivação estava na determinação de subverter um estado de coisas no Brasil, que faz com que suas regiões sintam-se marginalizadas em face da hegemonia do centro do país em muitos aspectos da vida nacional, entre eles, a produção cultural. ${ }^{3}$ Vejo Porto Alegre e Rio Grande do Sul como um lugar privilegiado por sua história social e política e sua situação geográfica únicas. Somos a confluência de três culturas, encontro de frialdade e tropicalidade. Qual é a base da nossa criação e da nossa identidade se não essa? Não estamos à margem de um centro, mas no centro de uma outra história (Ramil, 2004, p.28).

Ao colocar em xeque a centralidade do sudeste do país em termos de produção cultural, por meio da representação de um novo centro e de uma outra história, Vitor Ramil cria condições objetivas para a ação, que de fato ele próprio já houvera colocado em prática, ao retornar à Pelotas (no interior do Rio Grande do Sul) para buscar consolidar um mercado para sua música ao sul do país e nos países vizinhos. Daniel Drexler contribui para esta discussão ao dar ênfase na transformação do sentimento de periferia e isolamento:

Eu acho que uma das dicas mais importantes é passar dessa situação de nos sentirmos na periferia de algo e nos darmos conta que temos uma potencialidade muito boa por causa dessa sensação, e uma capacidade integradora mesmo em universos muito diferentes. Esse é o grande presente que temos agora. $[\ldots] \mathrm{E}$ o que eu acho interessante que fala Vitor Ramil e o que estamos falando agora é que de certo ponto chegou a hora de dizer: ok: vamos tomar as coisas em nossas mãos. Vamos deixar de estar vivendo uma vida que constantemente está sendo pautada por o que acontece no centro.

Percebe-se, neste sentido, que os artistas buscam a construção de uma nova territorialidade, um novo "centro", que possibilite a reprodução de seus trabalhos. Ao contestarem o "outro centro", os artistas passam a organizar e pautar suas ações em uma nova agenda, que inclui as cidades de seus parceiros, bem como novos locais de shows, parceiros culturais etc. Ao organizarem ou fazerem parte de shows, mostras e seminários que fazem alusão a essa nova centralidade, a representação deste território torna-se efetiva, sendo estes eventos marcadores importantes desta territorialidade em construção. 
Espetáculos como "Porto Alegre Montevideo, Sin Fronteras", "Lagunas y Lagoas", "Aires de la pampa alegre", "Yakupampa”, "Rumbos, Músicas del Sur", "Latinoamericana" entre outros, expressam não só nominalmente, mas em sua concepção, a existência de uma realidade vivida, que é transfronteiriça.

Há de frisar ainda o papel dos agentes culturais públicos e privados na afirmação das representações desta rede de músicos. Como exemplo, o Festival de Inverno de Porto Alegre que em seu release afirma que

(...) a programação acentua outra vez seu sotaque platino. É um evento que já se consagrou na cidade, não só pelas atrações, mas pelo fato de aproveitar a circunstância específica do inverno portoalegrense que já originou, inclusive, a tentativa de criação de uma estética do frio (Vitor Ramil), algo que definiria a nossa singularidade cultural e nossa peculiar visão de mundo. Apostamos também na integração cultural com nossos hermanos platinos, sem esquecer de resgatar valores nacionais consagrados.

Já no material de divulgação do Unimúsica, uma programação mensal de música popular brasileira em Porto Alegre há mais de trinta anos, chama a atenção à apresentação de Daniel Drexler, reconhecendo suas concepções estéticas, e incluindo-o como o único artista estrangeiro do projeto daquele ano:

Drexler apresenta canção pop eletroacústica com marcada influência de gêneros folclóricos da bacia do Rio da Prata, como a milonga pampeana, o candombe, a chamarrita e a murga montevideana. Desde 2005, utiliza o termo "templadismo" para se referir a uma nova corrente estética integrada por músicos argentinos, uruguaios e do Rio Grande do Sul, que teria a presença dos reflexos topográficos, climáticos e demográficos regionais sobre a criação e uma atitude criativa aberta, assimilando as influências de um mundo globalizado.

Vê-se, portanto, um influxo de concepções como a Estética do Frio e o Templadismo para dentro de instituições públicas, seja reconhecendo-as como concepções de integração dos músicos da região, seja estabelecendo-as como um norte - ou melhor, como um sul - para ações programáticas na esfera cultural. $\mathrm{O}$ discurso da identidade platina também está posto, misturando seus elementos com a cultura brasileira. Tais representações são inegáveis no sentido da assunção de um caráter distinto na busca de diálogos com os países do Prata para formular uma 
identidade que se conecta com o Brasil e com a América hispanófona.

Por outro lado, analisamos a produção discográfica realizada no período 2010 - 2016. Consideramos de maneira particular a feitura de seis discos: três realizados por artistas em formato solo, com participação de parceiros; três realizados em dupla, com artistas de pelo menos dois países. O resultado indica uma grande densidade de músicos e pessoal técnico envolvido e diversos estúdios de gravação acionados, conforme Figura 2. Em nossa opinião essa produção fonográfica transfronteiriça ressalta $\mathrm{O}$ caráter transterritorial (HAESBAERT \& MONDARDO, 2011) das redes musicais analisadas.

Seja pelos shows coletivos de artistas das distintas nacionalidades, seja pelos eventos culturais promovidos por entes públicos e privados, seja pelo conjunto de produções fonográficas apresentadas, nota-se uma forte territorialização desta música, organizando artistas, produtores culturais e público em torno de um novo circuito de música popular que se articula em rede nas cidades dos distintos países envolvidos. Portanto, a consideração dos eventos musicais torna-se necessária, pois como afirma Romagnan (2000), a música se territorializa em grande medida a partir de festivais e animações musicais. Discutindo a noção de evento, Milton Santos afirma que "os eventos são, todos, Presente. Eles acontecem em um dado instante, uma fração de tempo que eles qualificam. Os eventos são, simultaneamente, a matriz do tempo e do espaço” (SANTOS, 2009, p.145). Como não se repetem duas vezes, os eventos são sempre novos: "quando eles emergem, também estão propondo uma nova história” (ibidem). Dessa forma, se pode ver que o evento musical, ao criar representações platinas, está também criando - de certa forma - o próprio espaço platino. E mais: cada evento e sua própria localização se tornam irradiadores dessas representações do espaço, disseminandoas. Dessa forma, aliando representação e ação, a prática musical se territorializa juntamente com a ideia de um espaço transfronteiriço platino.

Entende-se, assim, que a produção de uma territorialidade musical no espaço platino efetiva um trânsito de agentes culturais que possibilita a reprodução destes. Ao mesmo tempo, essas ações expressam a própria produção de significado para os artistas, ajudando-os a construir sua experiência de mundo, que também é coletiva, como expressa pelo compositor Richard Serraria, em entrevista. 
Nós também estamos nos dando conta que Porto Alegre passou o tempo de ligação entre Brasil, Uruguai e Argentina, e também sempre tivemos essa sensação de estarmos isolados, sempre um pouco... figuras curiosas pro resto do Brasil, nosso clima é diferente, nosso jeito de falar é diferente, tudo... E agora com o Mercosul sentimos que passamos a ser ponte entre essas culturas... estamos começando uma nova era de comunicação de troca, e romper também com certos preconceitos, que a

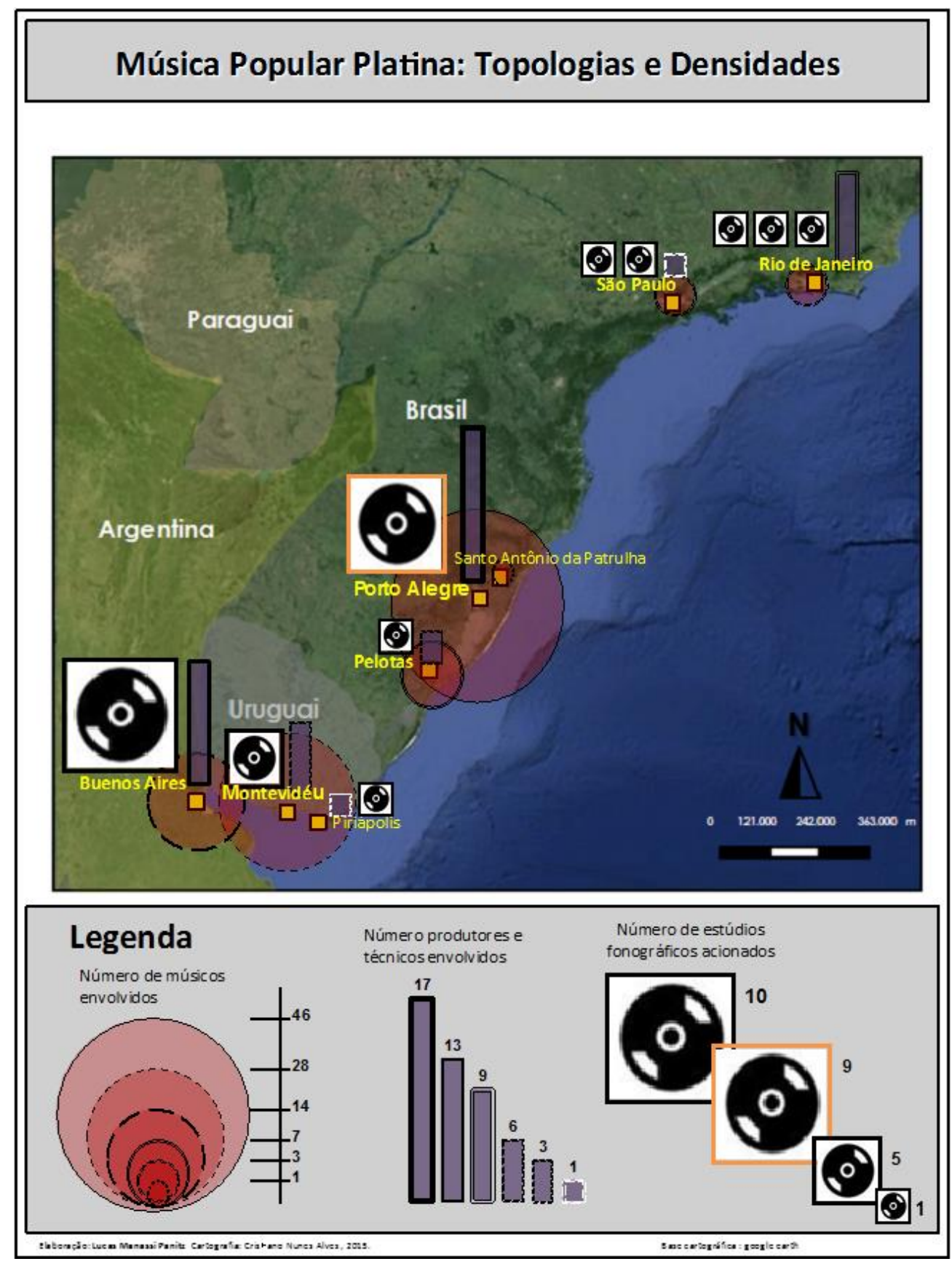

Figura 2: Síntese da produção fonográfica 2010-2016. Elaborado por Lucas Panitz e Cristiano Alves, 2016. 
gente começa a se sentir tão irmãos, que os preconceitos de mídia e de cultura vão caindo por terra.

Ao acompanhar os artistas ao longo da pesquisa, percebemos que a organização das ações não se dá como um projeto unívoco e manifesto, com plena convergência de opiniões, mas sim um diálogo permanente entre músicos parceiros que buscam pontos de contato entre suas produções musicais e suas concepções estéticas. Esses diálogos foram construídos também, e principalmente, fora de âmbitos formais: ao longo do processo de parcerias musicais, em ensaios e encontros pessoais diversos. Assim, criaram-se diversos grupos de parcerias transnacionais entre os músicos, com a organização de shows e discos.

\section{Recomposição territorial pela cultura}

Nas seções anteriores, mostramos como são elaboradas as representações do espaço, no sentido de uma prática geografizante, que busca descrever o espaço, se situar nele, e estabelecer analogias entre a composição musical e a paisagem, por exemplo. Junto a isso, o processo de representação do espaço se soma às práticas territorializantes dos artistas, em busca de um espaço para circulação de sua música. A música, portanto, tem contribuído sobremaneira para a criação de territórios e redes que expressam a integração regional no Prata, unindo músicos, público, produtores culturais e políticas da cultura. Entendemos que essa territorialidade musical [re]compõe o espaço platino: recompõe, porque traz à tona o reconhecimento de elementos culturais compartilhado antes do estabelecimento das fronteiras dos Estados-nação; compõe, porque o conteúdo das representações e das práticas vem transformado pela contemporaneidade e pela intencionalidade atual dos agentes.

O espaço platino torna-se possível através de micro-integrações, que se multiplicam através dos atores envolvidos. Essas, se dão na forma de rizoma (DELEUZE \& GUATTARI, 2000), expandindo a rede e criando diversos contextos de criação que podem escapar, e inclusive escapam, às concepções estéticas de uma platinidade, mas que ainda assim podem representar um processo de integração. Em nossa opinião esses processos não têm um estatuto de exceção. Eles dizem respeito às novas/velhas formas de experiência do espaço que transcendem os limites territoriais dos Estados-nação. Eventos como a Bienal de Arte do Mercosul, o Calendário Cultural Brasil-Uruguai, a Rede Mercocidades, a 
Associação de Universidades do Grupo Montevidéu, entre outros, fazem parte de uma constelação de iniciativas que estão pondo em prática uma integração regional de facto, na qual a cultura e a difusão do conhecimento estão no centro do debate. Documentar essas iniciativas, relatar e analisar essas integrações, possui contemporaneidade emergente nas ciências humanas face ao enfraquecimento das democracias na América Latina, e consequentemente da integração regional dos países latino-americanos.

\section{AGRADECIMENTOS}

$\mathrm{O}$ autor agradece à Coordenação de Aperfeiçoamento do Pessoal Docente de Nível Superior - CAPES, por meio das bolsas de mestrado, doutorado e pós-doutorado. Agradece também aos seguintes colegas, pelos diálogos que proporcionaram o amadurecimento desta pesquisa em bancas, mesas, seminários e conversas informais: Álvaro Heidrich, Yves Raibaud, Adriana Dorfman, Rogério Haesbaert, Júlia Andrade, Alessandro Dozena, Luis Felipe Rosado Murillo e Jodival Maurício da Costa.

\section{NOTAS}

* Professor Adjunto, Departamento Interdisciplinar, Universidade Federal do Rio Grande do Sul. Bolsa CAPES. E-mail: lucas.panitz@ufrgs.br. Geógrafo, mestre e doutor em Geografia pela UFRGS, com estágio-sanduíche na Université Bordeaux Michel de Montaigne e na Université Paris-Sorbonne. Tem experiência profissional em organização e análise de dados sócio-econômicos, cartografia temática aplicada ao desenvolvimento regional, além de pesquisas e projetos de extensão sobre redes no Mercosul, patrimônio, planejamento urbano participativo e mobilidade urbana. Possui os seguintes interesses de pesquisa: Geografia da Música; espacialidades da produção e da oferta cultural; representações do espaço nos produtos culturais; processos de integração sul-americana por meio da cultura; ciclomobilidade e mobilidade urbana sustentável; métodos qualitativos em pesquisa social. É vinculado ao Grupo de pesquisa, estudos e extensão em Geografia, Educação e Ambiente (SINERGEA/UFRGS) e ao Núcleo de Estudos Território e Resistência na Globalização (NUREG/UFF). Recebeu o Prêmio Maurício de Almeida Abreu 2011 de melhor dissertação conferida pela ANPEGE, e o Prêmio CAPES de Teses 2018 de melhor tese em Geografia.

1 E igualmente amplia e atualiza as discussões realizadas em Panitz (2013).

${ }^{2}$ Gaúcho é o gentílico de quem nasce no Rio Grande do Sul, estado no extremo sul do Brasil. Mas também se refere ao gaucho como tipo cultural da região platina surgido partir do século XVII, presente até hoje no folclore de ambos os países (Argentina, Brasil e Uruguai), embora cada qual com características distintas. O gaucho é conhecido pelo modo de vida peculiar sob o qual erigiram-se muitas representações míticas. A milonga e a payada, herdeiras crioulas do trovadorismo provençal, são duas manifestações musicais fortemente ligadas ao gaucho.

3 Todos os grifos em itálico nas falas dos entrevistados foram destacados pelo autor deste artigo. 
REFERÊNCIAS BIBLIOGRÁFICAS

AUBERT, Lauent. Mondes en musique. Genève: Musée d'ethnographie, 1991.

BENCKE, Glayson Ariel; CHOMENKO, Luiza; SANT'ANA, Danilo Menezes. O que é o Pampa. Nosso Pampa Desconhecido. Porto Alegre: Fundação Zoobotânica do Rio Grande do Sul, 2016.

BERQUE, Augustín. Paisagem-Marca, PaisagemMatriz: Elementos da Problemática para uma Geografia Cultural. In: CORREA, R. L.; ROSENDAHL, Z. Paisagem, Tempo e Cultura. Rio de Janeiro: EdUERJ, 1998. p. 84-91.

CANOVA, Nicolas; AUGUSTIN, Jean-Pierre. La musique au coeur de l'analyse géographique. Paris: L'Harmattan, 2014.

DARDEL, Eric. L'homme et la terre: nature de la realite geographique. [S.1.]: Editions du CTHS, 1990.

GUATTARI, Félix; DELEUZE, Gilles. Mil platôs 1. São Paulo: Editora 34, 2000.

DORMAN, Adriana; HEIDRICH, Álvaro; PANITZ, Lucas. Dossiê Geografia, Literatura e Música. Para Onde!?, v. 6, 2012.

DOZENA, Alessandro (org.). Geografia e Música: diálogos. Natal: EdUFRN, 2016.

DOZENA, Alessandro (org.). Dossiê Geografia, Músicas e Sons. Geograficidade, v. 8, 2018.

DREXLER, Daniel. Micromundo. Porto Alegre: MS2 Produtora, 2010. 1 disco sonoro.

FONTOURA, Luiz Fernando Mazzinni. Recordações do Pampa. Anais do X Encuentro. El mundo como Geografia. Rosario, 2008. 11p.

GUIU, Claire (dir.). Géographies et musiques : quelles perspectives? Géographie et Cultures 59, 2006.
HAESBAERT, Rogério. Território e multiterritorialidade: um debate. GEOgraphia, v. 9, n. $17,2007$.

HAESBAERT, Rogério; MONDARDO, Marcos. Transterritorialidade e antropofagia: territorialidades de trânsito numa perspectiva brasileiro-latino-americana. GEOgraphia, v. 12, n. 24, p. 19-50, 2011.

HALL, S. (Ed). Representation: cultural representations and signifying practices. London: Sage, 1997.

HEIDRICH, Alvaro Luís. Território e Cultura: argumento para uma produção de sentido. In: HEIDRICH, Alvaro Luís.; DA COSTA, Benhur Pinós.; PIRES, Cláudia Luísa Zeferino. Maneiras de ler Geografia e Cultura. Compasso: Porto Alegre, 2013, p. 53-60.

HOY, Diário. Entrevista con Daniel Drexler. $2006 . \quad$ Disponível em: $<$ www.diariohoy.net/notas/verNoticia.phtml/htm 1/228974>. Acesso em: 30 jul. 2007.

JODELET, Denise. Representações sociais: um domínio em expansão. In: JODELET, Denise (org.). As representações sociais. Rio de Janeiro: EdUERJ, 2001. p.17-44.

JOVCHELOVITCH, Sandra. Psicologia social, saber, comunidade e cultura. Psicol. Soc. [online]. 2004, vol.16, n.2 [cited 2011-12-11], pp. 20-31.

KONG, Lily. Popular music in a transnational world: the construction of local identities in Singapore. Asia Pacific Viewpoint, v. 38, n. 1, p. 19-36, 1997.

KONG, Lily. Popular Music in Geographical Analyses. Progress in Human Geography, v.19. 1995. p.183-198.

LÉVY, Jacques. Le tournant géographique. Paris: Belin, 1999.

LEYSHON, Andrew; MATLESS, David; REVILL, George. The place of music. New York: Guilford Press, 1998. 
LUSSAULT, Michel. L'homme spatial: la construction sociale de l'espace humain. Paris: Seuil, 2007.

MARCUS, George. Ethnography in/of the world system: the emergence of multi-sited ethnography. Annual review of anthropology, v. 24, n. 1, p. 95$117,1995$.

MELLO, João Baptista Ferreira. O Rio de Janeiro dos Compositores da música popular brasileira -1928/1991 - uma introdução à geografia humanística. 1991. Dissertação (Mestrado em Geografia) - Curso de Pós-Graduação em Geografia, Universidade Federal do Rio de Janeiro, Rio de Janeiro 1991.

MOSCOVICI, S. Das representações coletivas às representações sociais: elementos para uma história. In: JODELET, D. (Org.). As representações sociais. Rio de Janeiro: EdUERJ, 2001. p.45-66.

PANITZ, Lucas Manassi. Geografia e música: uma introdução ao tema. Biblio 3W. Revista Bibliográfica de Geografia y Ciencias Sociales, v. 17 , n. 978 , p. 30, 2012 a.

PANITZ, Lucas Manassi. Por uma geografia da música: um panorama mundial e vinte anos de pesquisas no Brasil. Para Onde!?, v. 6, n. 2, p. 1-10, 2012 b.

PANITZ, Lucas Manassi. Pratiques musicales, représentations et transterritorialités en réseau entre l'Argentine, le Brésil et l'Uruguay. Géographie et cultures, n. 88, p. 149-168, 2013.

PANITZ, Lucas Manassi. Redes musicais e [re]composições territoriais no Prata: por uma geografia da música em contextos multilocalizados. Tese de doutorado. Porto Alegre: Universidade Federal do Rio Grande do Sul, 2017.

PANITZ, Lucas Manassi. MURILLO, Luís Felipe Rosado. Etnografia multilocalizada em Antropologia e Geografia. In: HEIDRICH, Álvaro Luiz; PIRES, Claudia Luisa Zeferino. Abordagens e práticas da pesquisa qualitativa em Geografia e saberes sobre espaço e cultura. Porto Alegre: Letra 1, 2016.
RAIBAUD, Yves. Géographie socioculturelle. L'Harmattan: Paris, 2011.

RAIBAUD, Yves. Territoires musicaux em regions. MSHA: Pessac, 2006.

RAMIL, Vitor. A estética do frio. IN: FISCHER, L. A. (Org.). Nós, os gaúchos. Porto Alegre: UFRGS, 1993. p. 262-270.

RAMIL, Vitor. A estética do frio. Pelotas: Satolep Livros, 2004.

RAMIL, Vitor. Ramilonga: A Estética do Frio. Pelotas: Satolep Music, 1997. 1 disco sonoro.

RAMIL, Vitor. Satolep. São Paulo: Cosac Naify, 2008.

RAPOPORT, Mario; CERVO, Amado Luiz. El Cono Sur: una historia común. Fondo De Cultura Economica USA, 2002.

REICHEL, Heloísa Jochims; GUTFREIND, Ieda. As raízes históricas do Mercosul: a Região Platina colonial. Editora Unisinos, 1996.

RELPH, Edward. As bases fenomenológicas da Geografia. Geografia, v. 4, n. 7, p. 1-25, 1979.

ROMAGNAN, Jean-Marie. La musique: un nouveau terrain pour les géographes. Géographie et cultures. Paris, n. 36, p. 107-126, 2000.

RÜCKERT, Aldomar Álvaro.; DIETZ, Circe Inez. Integração regional, a região transfronteiriça da bacia do Rio da Prata e os projetos de infraestruturas de conexão. Confins. Revue franco-brésilienne de géographie/Revista franco-brasilera de geografia, n. 17, 2013.

SANTOS, Milton. A natureza do espaço: técnica e tempo, razão e emoção. São Paulo: Edusp, 2009.

SUERTEGARAY, Dirce Maria. Espaço geográfico uno e múltiplo. Scripta Nova: revista electrónica de geografía y ciencias sociales, 2001. 


\section{RÉSEAUX MUSICAUX Et (RE)COMPOSITIONS TERRITORIALES DANS LE PLATA: VERS UNE GÉOGRAPHIE DE LA MUSIQUE}

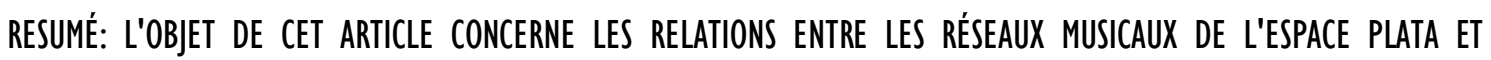
LEURS RÉPERCUSSIONS teRRITORIALES. À PARTIR D'UNE CONCEPTION DE RECHERCHE MULTLOCALISÉE, NOUS AVONS

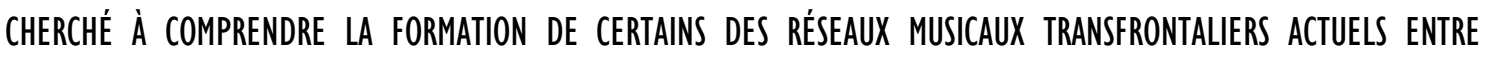
l'Argentine, le brésll et l'Uruguay. pour cela, Quatre aXes ont été articUlés. Le premier expose

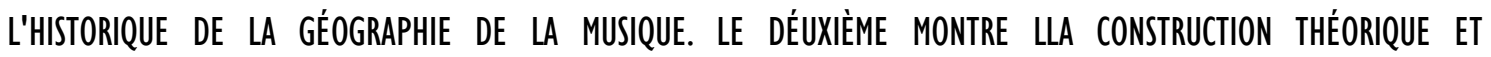
MÉthODOLOGIQUE DE LA RECHERCHE. LE TROISIÉME AXE PORTE SUR LES REPRÉEENT[ACTIONS] GÉOGRAPHISANTS ET

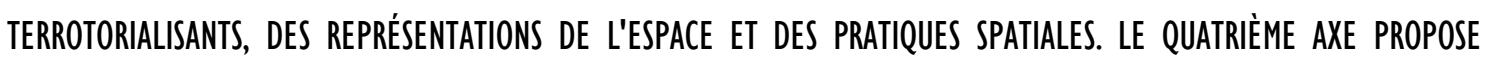
QUE LES RÉSEAUX EN QUESTION FAVORISENT UNE [RE]COMPOSITION TERRITORIALE DE LA CULTURE DU PLATA, EN

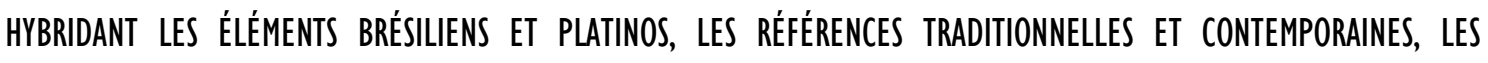
langues et les genRes musicauX. dans Cette [Re]COMPOSITION, des Villes comme porto alegre, pelotas,

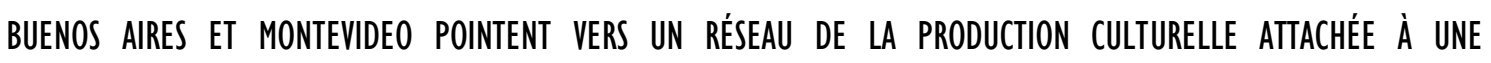
IMAGINATION GÉOGRAPHIQUE tranSFroNtaLIÈrE. ENFIN, NOUS DISCUTONS SUR LA COMPRÉHENSION DES RÉSEAUX

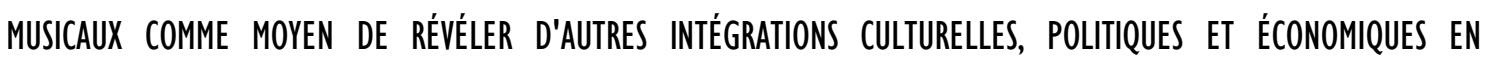
AMÉRIQUE DU SUD.

MOTS-CLÉ: GÉOGRAPHIE DE LA MUSIQUE; ESPACE PLATINO; L'ESTHÉtIQUE DU FROID; RESEAUX MUSICAUX.

\section{REDES MUSICALES Y (RE)COMPOSICIONES TERRITORIALES EN EL PLATA: POR UNA GEOGRAFÍA}

\section{DE LA MÚSICA}

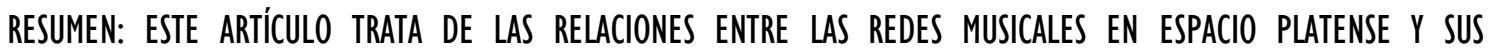
REPERCUSIONES TERRITORIALES. A PARTIR DE UN DISEÑO DE INVESTIGACIÓN MULTILOCALIZAdO, SE BUSCÓ ENTENDER LA FORMACIÓN DE ALGUNAS DE LAS ACTUALES REDES MUSICALES TRANSFRONTERIZAS ENTRE ARGENTINA, BRASIL Y URUGUAY. para ello, se articuló cuatro ejes. el primero expone el histórico de la geografía de la música. el SEGUNDO PLANTEA La CONSTRUCCIÓN teÓRICA Y METOdOLÓGICA DE LA INVESTIGACIÓN. El terCER EJE LLAMA ATENCIÓN PARA LAS REPRESENT[ACCIONES] GEOGRAFIZANTES Y TERRITORIALIZANTES, taNTO LAS REPRESENTACIONES DEL ESPACIO 


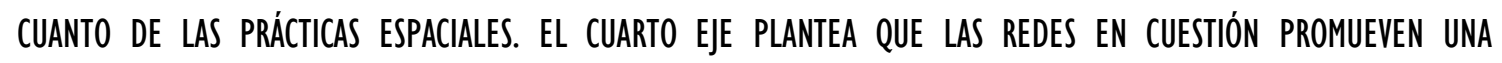
[RE]COMPOSICIÓN terRITORIAL DE LA CULtURAL EN EL PLATA, tranSCULTURANDO REFERENCIALES BRASILEÑOS Y RIOPLATENSES, TRADICIONALES Y CONTEMPORÁNEOS, E IDIOMAS Y GÉNEROS MUSICALES. EN ESA [RE]COMPOSICIÓN, CIUDADES COMO PORTO ALEGRE, PELOTAS, BUENOS AIRES Y MONTEVIDEO APUNTAN PARA UNA RED DE PRODUCCIÓN CULTURAL VINCULADO A UN IMAGINÁRIO GEOGRÁFICO TRANSFRONTERIZO. FINALMENTE, EL AUTOR LLAMA LA ATENCIÓN PARA LA COMPRENSIÓN DE LAS REDES MUSICALES COMO FORMA DE DESVELAR OTRAS INTEGRACIONES CULTURALES, POLÍTICAS Y ECONÓMICAS EN LA AMÉRICA DEL SUR.

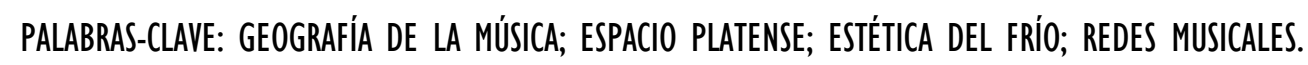

